ISSN 1814 - 5868 Basrah J. Agric. Sci., 34(Special Issue 1): 100-107, 2021

E-ISSN: 2520-0860

\title{
Characterization of Clay Soil and Zolite Powder as Materials for the Production of Irrigation Porous Pipes
}

\author{
Abdullahi Salisu ${ }^{1,3 *}$, Wayayok Aimrun ${ }^{1,2}$, Ahmad F. Abdullah ${ }^{1,2}$ \& Rowshon Md.
} Kamal $^{1,2}$

${ }^{1}$ Department of Biological and Agricultural Engineering, Faculty of Engineering, Universiti Putra Malaysia, 43400, UPM, Serdang, Malaysia

${ }^{2}$ SMART Farming Technology Research Center, Faculty of Engineering, Universiti Putra Malaysia, 43400, UPM, Serdang, Malaysia

${ }^{3}$ Department of Soil Science and Agricultural Engineering, Faculty of Agriculture, Usmanu Danfodiyo University, P.M.B. 2346, Sokoto, Nigeria

*Corresponding author E-mail: abdullahiskiru@gmail.com

Received 12 November 2019 ; Accepted 16 August 2021; Available online 20 August 2021

\begin{abstract}
The uses of clay pipes in irrigation water management are becoming popular, especially in arid and semi-arid soils. The study examined clay and zeolite materials for irrigation pipes, and this paper reported characteristic properties of these materials. Hydrometer, pychnometer and core sampler methods were for soil physical properties determination. Consistency tests using (Atterberg method) and analytical techniques (Scanning Electron Microscopy, SEM and Energy Dispersive Spectroscopy, EDS) for samples analyses. The results indicate the soil to contain $11 \%$ sand, $34 \%$ silt and $55 \%$ clay fractions and texturally classified as clay with a particle density of $1.58 \mathrm{~g} / \mathrm{cm}^{3}$ and bulk density $2.43 \mathrm{~g} / \mathrm{cm}^{3}$ respectively. Addition of zeolite at 3:1 clay/zeolite mix ratio shows liquid limit (LL) and plastic (PL) values to decreases from $50.7 \%$ to $43.7 \%$ and $27.6 \%$ to $27.3 \%$ while plasticity index, (PI) change from 23.2 to 16.7 respectively. The shrinkage rate decreases from $11.67 \%$ for raw clay to $8.92 \%$ for the treated sample. The EDS analysis shows both clay and zeolite samples to contain carbon, silica $\left(\mathrm{SiO}_{2}\right)$ and alumina $\left(\mathrm{Al}_{2} \mathrm{O}_{3}\right)$ as the major constituents with ferric oxide $\left(\mathrm{Fe}_{2} \mathrm{O}_{3}\right)$, potassium oxide $\left(\mathrm{K}_{2} \mathrm{O}\right)$ and cobalt (Co) as the minor constituents. The major constituents contribute 89.26 and 94.4\% while minor contribute 10.74 and $5.59 \%$ in clay and zeolite samples. Modifying clay improved its workability, reduces cracking potential and absorption capacity and performance of porous clay pipes.
\end{abstract}

Keywords: Clay, plasticity, irrigation, morphology, consistency test, chemical Composition

\section{Introduction}

Water scarcity is one major production problem in arid and semi-arid regions, and farmers opted for the use of high-performance micro-irrigation techniques (Kandelous \& Šimůnek, 2010). Clay porous pipe is one of the techniques considered reliable to irrigate crops and conserve water (Akhtar et al., 2016; Batchelor et al., 1996; Rasheed \& Abid, 2017; Siyal et al., 2013), in which conveyance and application of water are simultaneously made (Das et al., 2009). In contrast to drip emitters and trickle, clay pipes have low production and 


\section{Salisu et al. / Basrah J. Agric. Sci., 34(Special Issue 1): 100-107, 2021}

installation costs coupled with its simplicity in operation, which make it a better alternative among farmers. Batchelor et al. (1996) consider the method as promising and effective in ensuring crop quality, yield improvement and overall water use efficiency. It is an efficient water-saving tool, especially in less developed countries of the world arid and semi-arid regions (Siyal \& Skaggs, 2009). The abundance and availability of clay deposits offer great opportunities to farmers in irrigation clay pipes production. Igbadun \& Barnabas (2013) stated that materials used to make clay pipes affect its performance as it influences discharge rate and hydraulic conductivities of the pipes. In previous works, researchers produced different types of clay pipes using 100 per cent clay, or clay in combination with other additives, such as mixed with sand (less fine than clay), rice bran, sawdust, rice straw in the production process to improve hydraulic properties and quality of the pipes. For instance, Das et al. (2009) uses natural raw clay and produce pipes, Siyal et al., (2011; 2013) used potter's clay and produced clay pipes with wall thickness and diameters of $1.5 \pm 0.11$ and $13.10 \pm 0.20 \mathrm{~cm}$ and tapped one end for ease of connection. In another study, Igbadun \& Barnabas (2013) produced three different pipes with $100 \%$ clay, $95 \%$ clay with $5 \%$ fine sand and $90 \%$ clay with $5 \%$ fine sand and $5 \%$ sawdust of $2.5 \mathrm{~cm}$ thickness and $7.5 \mathrm{~cm}$ and $10 \mathrm{~cm}$ inner and outer diameters respectively. Similarly, another authors used locally available clay and mix with sawdust at 3:1 to produce the pipes.

Nanotechnology, with its vast potentials in many fields, may as well offers its application towards clay pipes performance improvement with nanomaterials as additives in the production process, this might open up a new area of interest by interwoven their attributes to improve the clay material. Clay and zeolites are crystalline aluminosilicate minerals that compose of different proportions of alumina and silica in different proportions and other minor constituents. Clay and zeolites have a variety of industrial, agricultural and environmental applications of human endeavor. Clays originate from complex weathering, transport, depositional and sedimentation processes over geological periods (Adelabu, 2012), and zeolite originate from naturally volcanogenic sedimentary mineral (Ghazavi, 2015)

As crystal lattice, with three-dimension structure, zeolite has cage-like microporous structures with regularly arranged cavities and pore channels (Colella \& Wise, 2014; Paul et al., 2017). This micro-porous structure often referred to zeolite as molecular sieves (Bruch et al., 2011) with the ability to lose or gain water and exchange their component elements (Mahesh et al., 2018). Zeolite loosely bound cations, with its ability to exchange ion, can absorb gases, catalyze reaction, hydrate and dehydrate materials (Ghazavi, 2015). Zeolites are used as desiccants, increase the sorption capacity, absorb water in large amounts and provide longer contact time to eliminate pollutants (Bruch et al., 2011). Zeolite as absorbent material serves dual purposes to functions for desalination and $\mathrm{pH}$ neutralization (Paul et al., 2017), an action that can greatly help in saline irrigation water management commonly found in drier areas. With Its tremendous application in agriculture like soil amendments, soil conditioning, improve infiltration, soil water holding capacity, surface adsorption and its macronutrients and micronutrients contain used to enhance plant nutritional uptake (Ozbahce et al., 2015).

To attain maximum irrigation efficiency, researchers offer guidelines on design criteria, production and operation of clay pipe 
products. Clays have the tendency to swell when they absorb water, shrink and harden as dries up sometimes-leaving cracks, which depend on clay plasticity, workability and malleability. Plasticity of clay is influenced by mineral composition, particle size distribution, organic substances or additives used (Andrade et al., 2011), In clay-water system, plasticity describe the rheological behaviour of the clay in a solid or liquid state. The authors attributed plasticity to be responsible when ceramic mass transformed into any shape upon pressure application. In structural production, require force to make the desired shapes, Andrade et al. (2011) suggested that such structures with materials or on clay base most retained its shape without excessive cracking or rupture when undergoing forming/deformation processes. Hence, the dire need to examine material properties used in the production of the pipes. In Nigeria, clay deposits are widely distributed in basements complex and sedimentary basins and constitute over $50 \%$ of the naturally occurring non-metallic resources. However, it is highly underutilized except for a few pockets of industries that harness it in the production of ceramic wares and structural products (Adelabu, 2012). Based on the background as mentioned above, the study employed physical, consistency and analytical techniques, to evaluate zeolite and widely used pottery clay, aimed at clay pipes production for irrigation purpose.

\section{Materials \& Methods}

\section{Sample collection and preparation}

A granular form of zeolite purchased from D SYIRA Enterprise (NS0048095-H) Seri Kembangan, Selangor, Malaysia, and clay collected from Rege clay fit located in Rege town, Kano state, Nigeria. With the aid of shovel and hand trowel, clay samples were collected from different positions along the diagonals of the collection pits, and the samples combined to form the composite sample. Similarly, the undisturbed sample was collected using core samplers for bulk density determination. From the composite sample, a portion was collected, stored in polythene bags and bring to the laboratory for preparation and analyses. The soil sample air-dried at room temperature; grind using pestle and mortar, pulverise, and allow passing through 425 microns sieve mesh then stored in plastic bags for further physical properties and consistency tests analyses. In the same manner, zeolite was ground and pass through the same sieve and package in polythene bags for further use.

\section{Physical properties of the soil}

Soil physical properties analyses and consistency tests was conducted in Soil and Water Conservation Laboratory of Biology and Agricultural Engineering whereas analytical analyses done in Materials Characterization Laboratory of the Department of Chemical and Environmental Engineering. Soil particle distribution, particle density and bulk density of the soil were determined using standard hydrometer method (ASTM D422), pychnometer method (ASTM D854) and standard drive-core sampler method (ASTM D2937), respectively.

\section{Atterberg Consistency and linear shrinkage tests}

Atterberg consistency tests ASTM D4318-10 method was for the determination of liquid limit (LL) and plastic limit (PL). To the treated sample, 3 parts clay mixed with 1 part of zeolite to obtain 3:1 ratio, and used mechanical shaker to mix for uniform and homogeneous sample thoroughly. The Atterberg limits (using Casagrande apparatus) test was performed for raw clay (untreated) and zeolitemodified (treated) clay as outlined in ASTM D4318-10 test method (ASTM, 2010). The 
plasticity index (PI) given as (PI=LL-PL) calculated from the differences of the liquid and plastic limits determined values. The shrinkage limit was performed according to the ASTM D427-04 standard method were a portion of liquid limit test paste was used and filled the troughs for the linear shrinkage test.

\section{Scanning electron microscopy (SEM) and energy dispersive spectroscopy (EDS)}

The morphology and microanalysis of clay and zeolite samples were determined by scanning electron microscopy equipped with energy dispersive spectroscopy (EDS) component using HITACHI (Model S-3400) machine. The machine provides for high highresolution and magnification images when the produced electrons beam scans the specimen and reflects rays to form the image in a raster pattern. Prepared clay and zeolite samples were placed on a tape attached to the sample holder, then placed inside the SEM machine vacuum chamber for scanning, and the obtained images from secondary electron (SE) detector were viewed from a computer monitor. The machine was operated at an accelerating voltage of $10 \mathrm{kV}$ and working distance (WD) of 4100 um having Emission Current of $119000 \mathrm{nA}$ to capture the images at a magnification of 3000 . Similarly, on aluminum holder placed about $0.5 \mathrm{~g}$ each of clay and zeolite sample and put inside the vacuum chamber of the machine for elemental and chemical content analyses using the component of Energy Dispersive X-ray Spectroscopy. The machine was operated at an acceleration voltage of $20 \mathrm{kV}$, at a scan rate of $2^{\circ}$ and take-off angle of 35 degrees.

\section{Results \& Discussion}

\section{Physical properties}

The index properties of Rege clay soil and zeolite as listed in table (1), showing some clay physical properties and consistency properties of clay and zeolite modified clay samples. The particle size analysis indicates the soil to content $11 \%$ sand, $34 \%$ silt and $55 \%$ clay fractions and in accordance with United State Department of Agriculture (USDA) soil textural triangle classified as clay. Similarly, found the soil particle and bulk densities to be 1.58 and $2.43 \mathrm{~g} / \mathrm{cm}^{3}$ respectively. The Consistency test results indicate liquid limit (LL) to be $50.7 \%$, plastic limit (PL) $27.6 \%$ and plasticity index (PI) 23.2 for untreated clay and classified as clay of high plasticity $(\mathrm{CH})$ following the Unified Soil Classification System (USCS) classification. Meanwhile, the LL PL and PI for the zeolite treated clay was $43.7 \%, 27.3 \%$ and $16.7 \%$ on the same scale and the treated clay change to soil of intermediate plasticity $(\mathrm{CI})$. The result is in agreements with similar soil analysis in (Soltani et al., 2019), proving the assertion that use of additives affects the soil plasticity properties (Nakhli et al., 2017; Andrade et al., 2011; Soltani et al., 2019). The liquid limit (LL) for the untreated was higher than the treated sample, and this shows more water was absorbed in its void space. Therefore, have higher swelling potential and hold a large amount of water as compared to when treated with zeolite, were the LL value decreased to $43.7 \%$. The change in the plastic limit (PL) values was slightly between untreated and treated clay samples. The shrinkage rate reduces from an initial value of $11.67 \%$ for untreated to $8.92 \%$ for the treated sample. This result is in line with Mishra et al. (2008) that when clay soil is exposed to a slight change in moisture content would lead to 
volumetric changes, which may result to formation of crack surfaces. Irrespective of the drying process adopted, clays with higher PI has greater potential to crack, and the addition of zeolite have lower the PI thereby lowering the pipes cracks potential. Similar scenario applied to excessive shrinkage when soils are restrained; it leads to cracking in clay soils due to consistent moisture loss while undergoing shrinkage, a phenomenon that can generate high negative pore pressure on the drying soil mass.

Table (1): Physical and consistency properties of soil.

\begin{tabular}{|c|c|c|c|}
\hline Physical properties & & & \\
\hline Percentage fraction ${ }^{\mathrm{a}}$ & $11 \%$ sand & $34 \%$ silt & $55 \%$ clay \\
\hline Textural class (USDA Classification) $)^{\mathrm{a} 1}$ & Clay soil & & \\
\hline Bulk density ${ }^{\mathrm{b}}\left(\mathrm{g} / \mathrm{cm}^{3}\right)$ & 2.43 & & \\
\hline Particles density ${ }^{\mathrm{c}}\left(\mathrm{g} / \mathrm{cm}^{3}\right)$ & 1.58 & & \\
\hline Consistency test: & Clay & & Clay treated with zeolite \\
\hline Liquid limit $(\%)^{\mathrm{d}}$ & 50.7 & & 43.7 \\
\hline Plastic limit $(\%)^{\mathrm{d}}$ & 27.6 & & 27.3 \\
\hline Plasticity index $(\%)^{\mathrm{d}}$ & 23.2 & & 16.7 \\
\hline Shrinkage limit $(\%)^{\mathrm{e}}$ & 16.4 & & 8.92 \\
\hline
\end{tabular}

${ }^{\mathrm{a}}$ Hydrometer method (ASTM D422), ${ }^{\mathrm{a}}$ USDA textural triangle, ${ }^{\mathrm{b}}$ Standard drive-core sampler method (ASTM D2937),

${ }^{\mathrm{c}}$ pychnometer method of particle density determination ASTM D854, ${ }^{\mathrm{d}}$ Atterberg limits tests (ASTM D4318-10) test method,

e Shrinkage limit (SL) test method ASTM D427- 04

Table (2): Elemental and chemical composition of clay and zeolite samples

\begin{tabular}{llllll}
\hline *Element & \multicolumn{2}{l}{ Weight (\%) } & \multicolumn{2}{c}{$*$ Composition } & \multicolumn{2}{c}{ Compound (\%) } \\
\hline & Clay & Zeolite & & Clay & zeolite \\
\hline $\mathrm{C}$ & 43.09 & 48.38 & $\mathrm{C}$ & 43.09 & 48.38 \\
\hline $\mathrm{O}$ & 26.76 & 25.31 & $\mathrm{SiO}_{2}$ & 33.47 & 37.43 \\
\hline $\mathrm{Si}$ & 15.65 & 17.50 & $\mathrm{Al}_{2} \mathrm{O}_{3}$ & 12.70 & 8.60 \\
\hline $\mathrm{Al}$ & 6.72 & 4.55 & $\mathrm{Fe}_{2} \mathrm{O}_{3}$ & 9.01 & 3.09 \\
\hline $\mathrm{Fe}$ & 6.30 & 2.16 & $\mathrm{~K}_{2} \mathrm{O}$ & 1.46 & 2.38 \\
\hline $\mathrm{K}$ & 1.21 & 1.97 & $\mathrm{Co}$ & 0.27 & 0.12 \\
\hline $\mathrm{Co}$ & 0.27 & 0.12 & & & \\
\hline
\end{tabular}

*Energy Dispersive Spectroscopy (EDS) method

\section{SEM/EDX Analyses}

The results of elemental and chemical composition analysis of clay and zeolite samples shown in table (2), while the sample micrograph images are in figs. ( 1 and 2 ) below.
The result obtained from the EDXS component of SEM machine shows that both clay and zeolite are amino silicate materials with silica and alumina as the major constituents and oxide of $\mathrm{Fe}, \mathrm{K}$ and $\mathrm{Co}$ as the minor constituents. 


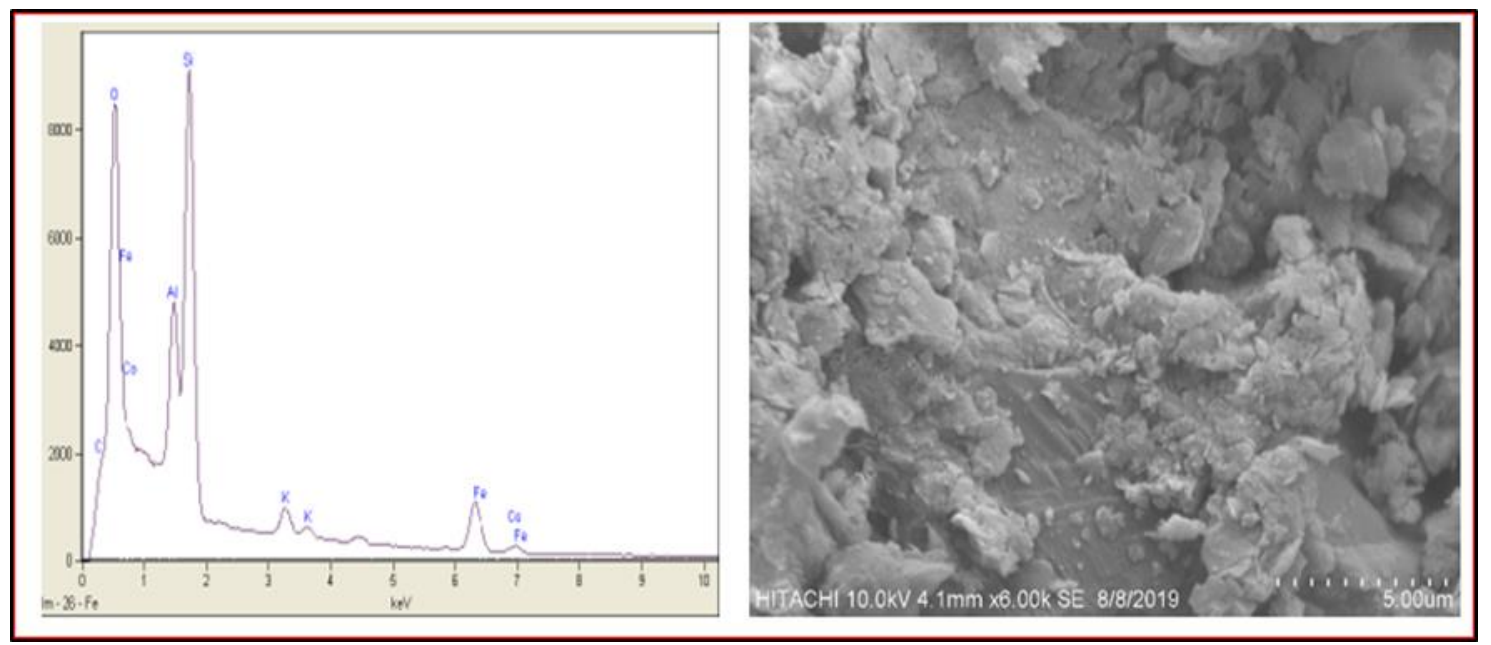

Fig. (1): EDS spectrum showing chemical element content and SEM micrograph of clay sample.

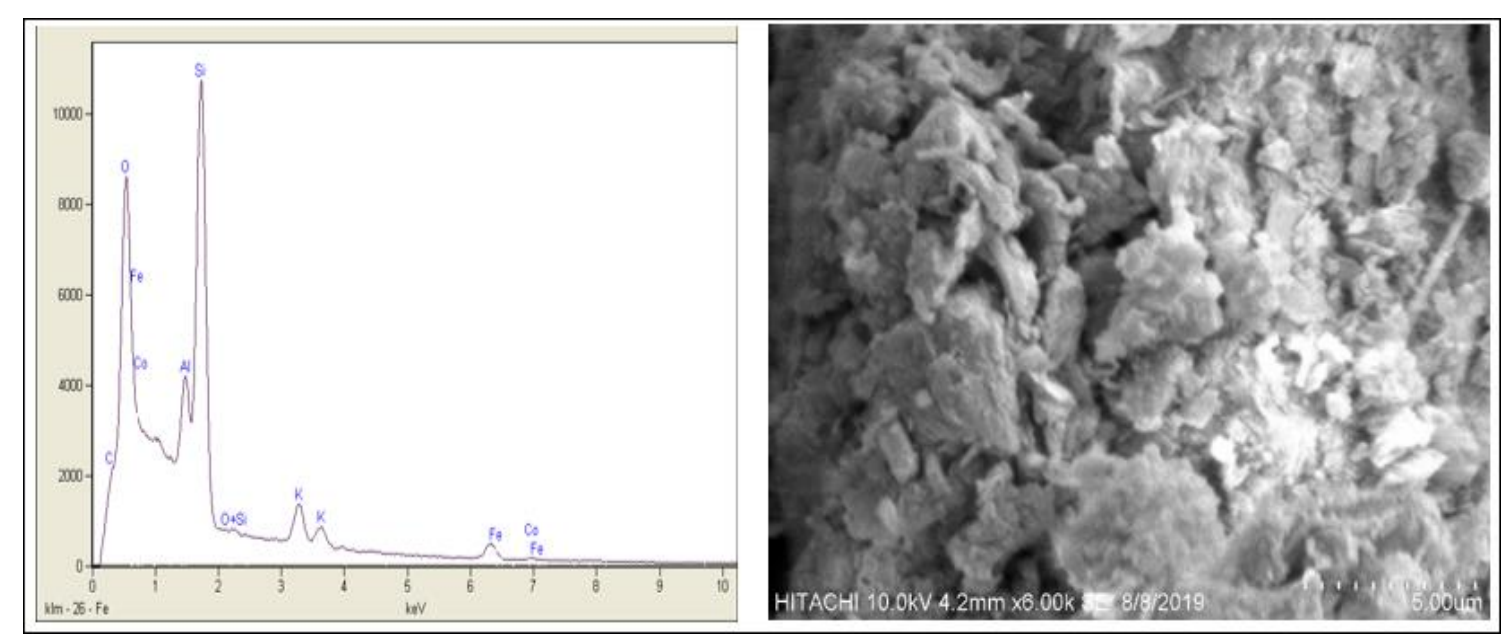

Fig. (2): EDS spectrum showing chemical elements content and SEM micrograph of zeolite sample.

The scanning electron microscopy (SEM) and energy-dispersive X-ray spectroscopy (EDXS) signals from interactions of the electron beam with the sample produced raster images and EDX graphs. Fig. (1) shows the SEM/EDX analysis of the raw clay and that of the zeolite sample shown in fig. (2). From the SEM images, the microstructure of the clayey sample morphology revealed a plate-like shape with a smooth surface and high agglomeration. Whereas at same magnifications that of zeolite shows flaky-like structures with large surfaces. Clay micro- structural surface is dense with granulated texture.

\section{Conclusions}

The aim was to investigate characteristic properties of clay and zeolite as well as to study the effect of zeolite addition on consistency properties of clay soil. Physical properties such as particle distribution, bulk density and particle density of the soil were determined following ASTM standard procedures. Other properties examined were the upper and lower limit, plasticity index and linear shrinkage limit of the clay soil, and 
when zeolite was added to clay sample (treated sample) using Atterberg consistency tests method. Similarly, the analytical properties of morphology and microanalysis of the samples were studied using scanning electron microscopy (SEM) and energy dispersive spectroscopy (EDS) techniques. Results of particle size analysis show the soil to content $11 \%, 34 \%$ and $55 \%$ sand, silt and clay fraction respectively and texturally classified as clay soil. The particle density and bulk density of the soil were 1.58 and $2.43 \mathrm{~g} / \mathrm{cm} 3$, respectively. The consistency tests results showed raw clay to be of high plasticity $(\mathrm{CH})$. At the same time, the addition of zeolite decreases the plasticity to the clay to intermediate plasticity clay (CI), and this lower the cracking potential of the clay, which consequently improve on the produced pipes. Cage-like porous structures with regularly arranged cavities and pore can improve both absorption and discharge of water through the pipes. The EDXS result indicates both clay and zeolite to be of aluminosilicate materials, and the SEM morphological analyses show zeolite images to content flakes with large surfaces that can support high water absorption, unlike clay that exhibit dense plate-like structures. It recommended from the study to try other different mix ratios to perform similar analyses and compare results for the most effective and efficient pipes compositions.

\section{Acknowledgements}

The authors wish to acknowledge and thank the sponsors, Ministry of high education (MOHE) and Universiti Putra Malaysia under the research grant Nanomite-LRGS, grant No. $9443105 / 5526305$ for this research work.

\section{Conflicts of interest}

The authors declare that there is no conflict of interests.

\section{References:}

Adelabu, O. S. (2012). Documentation, Application and Utilisation of Clay Minerals in Kaduna State (Nigeria). (M. Valaskova \& G. S. Martynková, Eds.), Clay Minerals in Nature - Their Characterisation, Modification and Application. Janeza Trdine, 9, 51000, Rijeka, Croatia: InTech. https://scirp.org/reference/referencespapers.aspx?ref erenceid $=1789027$

Akhtar, M., Ahmed, M., Hayat, R., \& Stöckle, C. O. (2016). Is rainwater harvesting an option for designing sustainable cropping patterns for rainfed Agriculture? Land Degradation and Development, 27, 630-640. https://doi.org/10.1002/ldr.2464

Andrade, F. A., Al-qureshi, H. A., \& Hotza, D. (2011). Applied clay science measuring the plasticity of clays : A review, 51, 1-7. https://doi.org/10.1016/j.clay.2010.10.028

ASTM D4318-10, Standard Test methods for liquid limit, plastic limit, and plasticity index of soils, ASTM International, West Conshohocken, PA, 16pp. www.astm.org

Batchelor, C., Lovell, C., \& Murata, M. (1996). Simple microirrigation techniques for improving irrigation efficiency on vegetable gardens. Agricultural Water Management. https://doi.org/10.1016/S03783774(96)01257-7

Bruch, I., Fritsche, J., Bänninger, D., Alewell, U., Sendelov, M., Hürlimann, H., \& Alewell, C. (2011). Bioresource Technology Improving the treatment efficiency of constructed wetlands with zeolitecontaining filter sands. Bioresource Technology, 102, 937-941.

https://doi.org/10.1016/j.biortech.2010.09.041

Colella, C., \& Wise, W. S. (2014). The IZA Handbook of Natural Zeolites: A tool of knowledge on the most important family of porous minerals. Microporous and Mesoporous Materials, 189, 4-10. https://doi.org/http://dx.doi.org/10.1016/j.micromeso .2013 .08 .028

Das, A., Mukand, G. Æ., \& Babel, S. (2009). Effect of soil texture on the emission characteristics of porous clay pipe for subsurface irrigation. Irrigation Science, 27, 201-208. https://doi.org/10.1007/s00271-0080129-9

Ghazavi, R. (2015). The application effects of natural zeolite on soil runoff, soil drainage and some chemical soil properties in arid land area. 
Salisu et al. / Basrah J. Agric. Sci., 34(Special Issue 1): 100-107, 2021

International $\quad 13, \quad 172-177$.

https://www.cabdirect.org/cabdirect/abstract/201533

73756

Igbadun, H. E., \& Barnabas, J. (2013). Hydraulic Characteristics of Porous Clay Pipes for Subsurface Irrigation. The Pacific Journal of Science and Technology, 14, 40-47. https://www.scribd.com/document/222378698/Hydr aulic-Characteristics-of-Porous-Clay-Pipes-for-

Subsurface-Irrigation

Kandelous, M. M., \& Šimůnek, J. (2010). Numerical simulations of water movement in a subsurface drip irrigation system under field and laboratory conditions using HYDRUS-2D. Agricultural Water Management, $\quad 97, \quad 1070-1076$. https://doi.org/10.1016/j.agwat.2010.02.012

Mahesh, M., Thomas, J., Kumar, K. A., \& Bhople, B. S. (2018). Zeolite farming: a sustainable agricultural prospective. International Journal of Current Microbiology and Applied Sciences, 7, 2912-2924. https://www.ijcmas.com/7-5-

2018/Meharkure\%20Mahesh,\%20et\%20al.pdf

Mishra, A. K., Dhawan, S., \& Rao, S. M. (2008). Analysis of Swelling and Shrinkage Behavior of Compacted Clays. Geotechnical and Geological Engineering, 26, 289-298. https://doi.org/10.1007/s10706-007-9165-0

Nakhli, S., A. A., \& Delkash, M., Bakhshayesh, B. E., \& Kazemian, H. (2017). Application of zeolites for sustainable agriculture: A review on water and nutrient retention. Water, Air, Soil Pollution, 228, 134. DOI: $10.1007 / \mathrm{s} 11270-017-3649-1$

Ozbahce, A., Tari, A. F., Gönülal, E., Simsekli, N., \& Padem, H. (2015). The effect of zeolite applications on yield components and nutrient uptake of common bean under water stress. Archives of Agronomy and Soil Science, 61, 615-626. https://doi.org/10.1080/03650340.2014.946021

Paul, B., Dynes, J. J., \& Chang, W. (2017). Modified zeolite adsorbents for the remediation of potash brineimpacted groundwater: Built-in dual functions for desalination and $\mathrm{pH}$ neutralisation. Desalination, 419, 141-151. https://doi.org/10.1016/j.desal.2017.06.009

Rasheed, Z. K. \& Abid, M. B. (2017). Numerical Modeling of Water Movement from Buried Vertical Ceramic Pipes through Coarse Soils. Al-Khwarizmi Engineering Journal, 13, 164-173. https://doi.org/10.22153/kej.2017.06.003

Siyal, A. A., \& Skaggs, T. H. (2009). Measured and simulated soil wetting patterns under porous clay pipe sub-surface irrigation. Agricultural Water Management, 96, 893-904. https://doi.org/10.1016/j.agwat.2008.11.013

Siyal, A. A., Siyal, A. G., \& Hasini, M. Y. (2011). Crop production and water use efficiency under subsurface porous clay pipe irrigation. Pakistan Journal of Agriculture Agricultural Engineering and Veterinary Sciences, 27, 39-50.

Siyal, A. A., Van Genuchten, M. T., \& Skaggs, T. H. (2013). Solute transport in a loamy soil under subsurface porous clay pipe irrigation. Agricultural Water Management, 121, 73-80. https://doi.org/10.1016/j.agwat.2013.01.005

Soltani, A., Deng, A., Taheri, A., \& Sridharan, A. (2019). Consistency limits and compaction characteristics of clay soils containing rubber waste. Proceedings of the Institution of Civil Engineers: Geotechnical Engineering, 172, 174-188. https://doi.org/10.1680/jgeen.18.00042 